Short title: Pennisetum ciliare Invasion Strategy

Satellite Patches, Patch Expansion, and Doubling Time as Decision Metrics for Invasion Control: Pennisetum ciliare Expansion in Southwestern Arizona

Jaron D. Weston ${ }^{1}$, Mitchel P. McClaran², Richard K. Whittle ${ }^{3}$, Christian W. Black ${ }^{4}$, Jeffrey S. Fehmi $^{2 *}$

${ }^{1}$ Graduate student, University of Arizona, School of Natural Resources and the Environment, Tucson, AZ; ${ }^{2}$ Professor, University of Arizona, School of Natural Resources and the Environment, Tucson, AZ; ${ }^{3}$ Wildlife Biologist, $56^{\text {th }}$ Range Management Office, U.S. Air Force, Luke AFB, AZ.

${ }^{4}$ Geographer, $56^{\text {th }}$ Range Management Office, U.S. Air Force, Luke AFB, AZ.

Author for Correspondence: J. Fehmi. University of Arizona, 1064 E Lowell St, Tucson, AZ 85719. (E-mail: jfehmi@email.arizona.edu)

Essential variables to consider for an efficient control strategy of invasive plants include dispersion pattern (i.e. satellite or invasion front) and patch expansion rate. These variables were demonstrated for Buffelgrass [Pennisetum ciliare (L.) Link], a C4 perennial grass introduced from Africa, which has invaded broadly around the world. The study site was along a roadway in southern Arizona (USA). The $P$. ciliare plant distributions show the pattern of clumping associated with the satellite (nascent foci) colonization pattern (average nearest neighbor test, $z$-score $-47.2, p<0.01$ ). The distance between patches ranged from $0.743 \mathrm{~km}$ to $12.8 \mathrm{~km}$ with an average distance between patches of $5.6 \mathrm{~km}$. Median patch expansion rate was $271 \%$ over the three-year monitoring period versus $136 \%$ found in other studies of established $P$. ciliare patches. Targeting $P$. ciliare satellite patches as a control strategy may exponentially reduce the areal doubling time while targeting the largest patches may have less effect on the invasion speed.

\title{
Management Implications
}

The results from this study imply that prioritizing discovery and control of newly invaded areas over the removal of known large invaded areas has the potential to be an effective and tractable invasive species control strategy for $P$. ciliare. Finding new $P$. ciliare occurrences may be difficult within large uninvaded areas and perhaps may require more public justification compared to controlling known invaded areas. Removing newly established $P$. ciliare plants the furthest from the existing invaded areas has the potential to reduce $P$. ciliare invasion rates from exponential expansion to a more tractable quadratic expansion. Given the potential high expansion rates of $P$. ciliare, managers of the lands prone to $P$. ciliare invasion likely need to impress policymakers and funding bodies of the need for timely action. Delaying the start of a control program by even a few years might allow the invaded area to expand beyond the economic threshold for control action.

Key words: Sonoran Desert; Management strategy; Invasive species; Clustered pattern; Seed dispersion. 
Introduced grasses vigorously invade across a wide range of arid and semi-arid ecosystems and have colonized all continents, including Antarctica (D'Antonio and Vitousek 1992; Molina-Montenegro et al. 2012). Once introduced, invasive grasses have been shown to outcompete native species through a variety of strategies: particularly faster uptake of ecosystem-limited resources especially when transitioning from a dormant state (Van Auken and Bush 1990; Ward et al. 2006), growing densely to obstruct other species from insolation (Bush and Van Auken 1987), and high propagule pressure (Lonsdale 1999; Richardson and Pyšek 2006). Invasive grasses can also alter the ecosystem fire regime which has been shown to be a primary factor of long-term successful grass invasion, even in competition with native grasses (D’Antonio and Vitousek 1992). For example, in Australia, invasive Rhodesian blue grass (Andropogon gayanus Kunth) produced a fuel load many times greater than the areas dominated by native grasses. This significantly altered the fire regime in favor of $A$. gayanus and sped up the rate of its invasion (Rossiter et al. 2003).

While the impacts of invasive grasses have been well documented, finding successful strategies to control or remove invasive grasses remains difficult, particularly once the species begins to move beyond the site of initial introduction (DiTomaso 2000; DiTomaso et al. 2010). Plant dispersion patterns have been shown to be a particularly important characteristic of invasions (Sebert-Cuvillier et al. 2010; Lookingbill et al. 2014) and influence not just reinvasion risk, but can lead to exponentially greater expansion rates depending on the type of plant dispersion (Moody and Mack 1988; Cannas et al. 2006).

There are two primary, detectible plant dispersion patterns: (1) invasion along the edge of existing patches (i.e. an "invasion front", whereby new plants establish along the edges of the source population) and (2) establishment of satellite populations (i.e. "satellite dispersion", whereby new plants establish both along the front as well as in newly established patches distinct from the source population). These satellite populations become new source populations and this kind of dispersion can lead to exponentially greater invasion rates compared to an invasion front dispersion (Shigesada and Kawasaki 1997).

Invasion front and satellite dispersion require different control strategies. If an invasion front is the primary dispersion pattern, a removal strategy emphasizing encircling invaded patches would be efficient and the risk of reinvasion from distant source patches would be low (Cannas et al. 2006). Conversely, if satellite dispersion commonly occurs, then targeted removal of nascent satellite populations has been shown to best slow or control the invasion (Moody and Mack 1988). This is because new satellite establishment increases the area of imminent invasion risk. In such situations, research has suggested that removing the satellites furthest from invasion fronts will generally bring the greatest reduction further invasion risk (SebertCuvillier et al. 2010; Lookingbill et al. 2014).

In addition to understanding dispersion pattern, it is critical to understand cumulative expansion rate in order to formulate an effective control strategy (Fensham et al. 2013; Lookingbill et al. 2014). Expansion rates inform land managers about the total resources needed to control expansion of an invasive species (Olsson et al. 2012a), they allow determination of areas at greatest risk for further invasion (Higgins et al. 1996; Cannas et al. 2016), and they help managers estimate the consequences of lags between detection and control efforts. 
Buffelgrass [Pennisetum ciliare (L.) Link, synonym: Cenchrus ciliaris L.], a $\mathrm{C}_{4}$ perennial grass from Africa (Cox et al. 1988) with a nearly world-wide distribution (reviewed in: Rogstad 2008; Lyons et al. 2013), is an ideal species to test ideas about expansion rates to inform control strategies. The invasion success of $P$. ciliare, like most invasive grasses, is due in part to its seed dispersal (Ernst et al. 1992), low water requirements for germination (Ward et al. 2006), high drought tolerance, and quick uptake of water from senescence (Reynolds et al. 2004). Pennisetum ciliare can become dominant in the Sonoran Desert even without disturbances (Olsson et al. 2012b) but the cycle of dry-lightning-ignited fires fostered by $P$. ciliare threatens plant community conversion to an African-type grassland with little diversity and few native plants (McDonald and McPherson 2011; Olsson et al. 2012a; Lyons et al. 2013).

Mechanical removal and herbicides can successfully control $P$. ciliare, at least in the short-term (e.g. Jernigan et al. 2016), but land managers have struggled to develop successful long-term control strategies for large areas (Rogstad 2008). Reinvasion of $P$. ciliare has been linked to propagule pressure, seed dispersal radius, and seed bank persistence of 3-4 years (Winkworth 1971; Fensham et al. 2013). Thus, even if a local $P$. ciliare population is removed, land managers must continue managing for seedling emergence from the seed bank and recruitment from regional sources, due to propagule pressure and seed dispersal radius.

Olsson et al. (2012a) found that $P$. ciliare patches double in size an average of every 5.1 years, with a range of 2-7 years. However, the patches in the Olsson et al. (2012a) study were long-term, based on data collected from patches that had established 14 to 20 years before. These late-stage invasion results may reflect constrained patch expansion due to colonization of the majority of suitable habitat and may not be applicable to new invasions. This is especially relevant if there is a high incidence of satellite dispersion by $P$. ciliare because, if nascent satellites expand at a faster rate than existing larger patches as well as merge with other patches over time, the before and after expansion rate will include both the satellite and front effects. Since $P$. ciliare is still actively invading in the Sonoran Desert and throughout the world, the purpose of our study was to determine $P$. ciliare dispersion patterns and expansion rates of newly invaded territories, focusing specifically on expansion of satellites, patch size, and patch growth rates. If it can be determined that $P$. ciliare invades using a satellite dispersion strategy, land managers can improve their control strategies by targeting new satellite populations. Further, if expansion rates of new patches are faster than for long-standing patches, land managers will have more accurate timeline to design their removal strategies.

\section{Materials and Methods}

\section{Study Area}

The study was conducted on the right-of-way of a roadway in southern Arizona, USA $\left(32^{\circ} 51^{\prime} 16^{\prime \prime} \mathrm{N}, 112^{\circ} 46^{\prime} 06^{\prime \prime} \mathrm{W}\right)$. The paved public roadway traverses a military reservation. The contiguous area within $1 \mathrm{~km}$ of the study area was wildlands. The roadway has little traffic and connects the town of Ajo, Arizona to Gila Bend, Arizona, both with populations of a few thousand people. There was an average distance of $60 \mathrm{~m}$ from the edge of the roadway to a fence. The fence defined the right-of-way which was physically changed by the road (e.g. through water distribution and likely increased water availability). The relatively undisturbed land outside the right-of-way remained uninvaded throughout the study period. Data for the dispersion pattern analysis was collected along $16 \mathrm{~km}$ of the west side of the roadway, for a 
total area of 1 ha (Figure 1). Data for the patch expansion analysis came from $P$. ciliare patch boundaries which were monitored along a $56 \mathrm{~km}$ stretch of the roadway (Figure 1), for a total area of 676 ha. Pennisetum ciliare was first noted in 2008 but not previously when doing driving surveys.

\section{Data Collection and Analysis - Dispersion Pattern}

In spring 2015, P. ciliare occurrences were identified from a vehicle driving up to $30 \mathrm{~km} / \mathrm{h}$ along the west side of the roadway. An accuracy assessment was conducted to evaluate the effectiveness of identifying $P$. ciliare from a vehicle. In areas identified from a vehicle as having few or no $P$. ciliare plants, $10300-\mathrm{m}$ segments of the dispersion pattern analysis study area were randomly selected and surveyed on foot to determine if $P$. ciliare were being missed by the sampling procedure. The 10 segments were rasterized into $1801,000 \mathrm{~m}^{2}$ cells and errors of omission and commission were calculated for each cell. For the accuracy assessment, 174 cells were expected to contain no $P$. ciliare and 6 were expected to have $P$. ciliare from the original drive survey. The on-foot accuracy assessment survey revealed that the 174 cells with no $P$. ciliare were accurately surveyed. Three of the cells that predicted $P$. ciliare contained $P$. ciliare while the other 3 cells incorrectly predicted $P$. ciliare. This returned a cell accuracy of $96.7 \%$ which exceeds the recommended level of $85 \%$ by Foody (2002).

Once potential $P$. ciliare occurrences were identified for the dispersion pattern data collection, locations of each individual, with an individual defined as being separate from neighboring plants by more than $10 \mathrm{~cm}$, were recorded (GPS 60, Garmin, Schaffhausen, Switzerland) to an accuracy of $\pm 3-5 \mathrm{~m}$. The locations were used to determine dispersion pattern using the Average Nearest Neighbor (ANN) method (ArcGIS version 10.2.2, ESRI, Redlands, CA). The ANN test determines the dispersion pattern (dispersed, random, or clustered) of points (i.e. P. ciliare individuals) within a defined area by computing the ratio of the actual mean distance between each plant and its nearest neighbor to the expected mean distance of each plant and its nearest neighbor. The lower the ratio, the more clustered a data set, while a higher ratio is a more dispersed dataset (pending statistical significance). A ratio close to $1: 1$ is considered a random distribution. If $P$. ciliare distribution were dispersed or random under the ANN, the spread would be an invasion front. A clustered classification from the ANN would indicate satellite dispersion.

\section{Data Collection and Analysis - Expansion Rate}

From 2011-2013, patches of $P$. ciliare were observed October through December along both sides of the roadway. Patches were defined as 3 or more individuals, $\leq 0.5 \mathrm{~m}$ apart. We identified 36 patches along a $56 \mathrm{~km}$ stretch of roadway. Patch outlines were recorded (Trimble Geo XH, Sunnyvale, $C A$ ) to an accuracy of $\pm 20 \mathrm{~cm}$ post correction.

The expansion rate of each patch was calculated as the percent change in area per year. Pennisetum ciliare patches were analyzed only if there were patch data for all three years. A pooled site model (PSM) was also created by summing all patches to produce an aggregate for the entire study area to estimate cumulative expansion (Olsson et al. 2012a). To account for patch coalescence, patches in the final year of data collection (2013) were enumerated. Each 
patch in the previous years of data collection that intersected or occurred within one of the 2013 enumerated patches was assigned the number of its corresponding 2013 patch.

\section{Results and Discussion}

Dispersion Pattern

The individual plant distributions show the pattern of clumping associated with the satellite dispersion pattern (average nearest neighbor test, $z$-score $-47.2, p<0.01$ ) which is distinctly different from a random or dispersed pattern found in an invasion front (Figure 2). A total of $652 P$. ciliare individuals were identified along the $16 \mathrm{~km}$ roadway segment. The individuals occurred in 6 distinct patches, with patches ranging in size from $8 \mathrm{~m}^{2}$ to $2997 \mathrm{~m}^{2}$ (Figure 3). The distance between patches ranged from $0.743 \mathrm{~km}$ to $12.8 \mathrm{~km}$, based on mean center. The average distance between patches was $5.6 \mathrm{~km}$.

While we did not define an a priori threshold for determining a satellite patch other than the finding of Ernst et al. (1992) that $P$. ciliare seeds tended to disperse less than 10 meters from parent plants, our patch distribution results show $P$. ciliare invading with a satellite dispersion strategy along a roadside. The increase in satellite patches at least implies the theoretical potential for a compounding growth rate constrained only by the remaining uninvaded areas suitable for $P$. ciliare growth and sufficient rainfall to support seedling establishment. The models of Shigesada and Kawasaki (1997) imply that once $50 \%$ of the available suitable area becomes invaded the expansion rate will slow and asymptotically approach the system being fully invaded. While validating this theoretical change in rate for $P$. ciliare may be interesting, controlling the invasion will hopefully have a high enough priority to prevent full invasion.

The models of Moody and Mack (1988), Shigesada and Kawasaki (1997), and Cannas et al. (2006) all found that plant invasions expand exponentially slower when land managers target satellite populations during control than when they do not. Specifically, Moody and Mack (1988) found that targeting satellite populations exponentially improved the control of a plant invasion for an area, if a minimum of $15 \%$ of satellites are removed. Given the substantial consequence for ignoring satellite patches, the problem facing managers appear twofold. First, satellite patches must be detected soon after establishment which in our example would be made difficult by satellite patches occurring an average of $5.6 \mathrm{~km}$ from the presumed source patch. This might imply searching a prohibitively large area of nearly $100 \mathrm{~km}^{2}$ for newly established satellites although as we discuss below the roadway could have greatly augmented seed movement. Second, prioritizing discovery and control of small patches over the known large source patches may seem counter intuitive to both the public and resource managers and may result in an inconsistent approach over time.

\section{Expansion Rate}

Pennisetum ciliare year-to-year patch expansion varied from $-0.26 \%$ to $21,904 \%$. Most patches (75\%) experienced more growth from 2011 to 2012 than from 2012 to 2013 but, 25\% decreased in size from 2012 to 2013. There was no observed relationship between expansion rate and patch size (Figure 4) nor between patch size and contribution to the growth of the pooled-site model (PSM), $\mathrm{R}^{2}=0.0048, \mathrm{p}=0.046$. The PSM - a sum of the area covered by all $P$. ciliare patches on the study area - showed that the cumulative invaded area increased in both 
2012 and 2013 (Figure 5), but more from 2011 to 2012 (117\%) than from 2012 to 2013 (69\%). The year-to-year increase did not correspond well with the recorded precipitation in Gila Bend, Arizona ( $48 \mathrm{~km}$ north of the center of the patch expansion study area) with the 2011,2012 , and 2013 precipitation of 106, 107, and $164 \mathrm{~mm}$ respectively versus a 1981- 2010 mean annual precipitation of $179 \mathrm{~mm}$ (DOC-NOAA 2018). The median patch size increase across the whole period of observation (from 2011 to 2013 ) was $271 \%$.

Our observed variability in expansion aligns with the descriptions of expansion rates by Johnson and Shonkwiler (1999), who concluded from a meta-study in the Great Basin region of the USA that invasive weed patch expansion was variable over time due to environmental factors. They also found that variable patch growth of invasive weeds led to significant economic impact to and difficulty of invasive species control. Schramm and Ehrenfeld (2012) found similar patch expansion variability during a Nepalese browntop [Microstegium vimineum (Trin.) A. Camus] invasion in the Sourland Mountains of west-central New Jersey, USA. Given that this was a forb in a mesic forest ecosystem, the variability appears to be somewhat common across invasions. Similarly, Olsson et al. (2012a) found variable $P$. ciliare patch expansion on sites in the Sonoran Desert. Some patches in the Olsson et al. (2012a) study decreased in size during different time periods, even given the longer duration of their study. For example, one patch decreased in size between 1990 and 1993 and another decreased in size from 1994 and 1997, despite an overall growth of each patch during the entire study (median patch size increase during the study period was $136 \%$ ).

The present study also aligned with Olsson et al.'s (2012a) doubling time results, which averaged 2.10 years compared to 2.16 years in the present study (based on data given in Olsson et al. (2012a) as percent change in area per year to match our methods). Removing the two longest doubling times (52.2 and 71.9 years) of the 36 total patches, the average doubling time of the present study ( 0.79 years) was less than half of Olsson et al. (2012a), suggesting that expansion rate for new invasions or smaller patches could be higher than for larger, established patches, due to the possible availability of suitable growing areas adjacent to the newly invaded territory. The expansion of the PSM further illustrates this point. The PSM (i.e. the combined area of all $P$. ciliare) of the present study expanded at a doubling rate 15.5 times faster than Olsson et al. (2012a) (0.37 years versus 5.82 years). However, there was not a compelling relationship $\left(R^{2}=0.0048, p=0.046\right)$ between patch size and growth rate in our study, as would be expected (Figure 4). We also expected smaller patches to consistently contribute more to the overall growth of the PSM. This was not true in our study, as smaller patches at less than $1,000 \mathrm{~m}^{2}$ (i.e. satellites) contributed $63 \%$ of the PSM growth the first year, but only $27 \%$ the second year (Figure 5).

Assuming circular $P$. ciliare patches for ease of calculation, patches expanded an average of $2.11 \mathrm{~m}$ from the edge of the previous year's patch. Patch expansion ranged from 0.02-12.7 $\mathrm{m}$, with a standard deviation of $2.57 \mathrm{~m}$. Patches greater than $1,000 \mathrm{~m}^{2}$ expanded a greater distance than patches less than $1,000 \mathrm{~m}^{2}$ (6.7 m compared to $2.6 \mathrm{~m}$ in 2011 and $10.2 \mathrm{~m}$ to $1.3 \mathrm{~m}$ in 2012). The results of average expansion for Olsson et al. (2012a) were similar at $2.86 \mathrm{~m}$ from the edge of the previous year on average, ranging from 1.92-5.72 $\mathrm{m}$ (when recalculating their data with our methods, for comparability). This corroborates the findings of Ernst et al. (1992), who found that $P$. ciliare seeds dispersed 0.60-7.26 meters from parent plants, based on wind speed and inflorescence height. While Ernst et al. (1992) noted that uncommon events such as 
whirlwinds or large storms could move seeds, the numbers tended to be small and the movement was concentrated among the lightest and least viable seeds. We observed established patches $\geq 700 \mathrm{~m}$ from the nearest neighboring established patches, implying that movement events must be common and contain sufficient amounts of viable seed. Given that our study site is along a rural roadway (roughly $8 \mathrm{~m}$ wide), the turbulence of large vehicles moving at high speed may have significantly contributed to seed movement. Illustrating our $P$. ciliare data graphically shows the potential difference in areal expansion between the front invasion and the satellite invasion (Figure 6).

Patch coalescence is another important behavior during an invasion because it represents a shift from invasion to expansion and connectivity of patches, leading to manifold increases in the impact a species has on the environment and increasing the invasion rate to neighboring areas. Davis et al. (2004) found that successful western U.S. marsh invader Smooth cordgrass (Spartina alterniflora Loisel.) produces significantly proportionately more seed (i.e. an Allee affect) once patch coalescence and density occurs, further promoting invasion. Robinson et al. (2008) found that patch coalescence of Prosopis spp. in Western Australia represented the establishment of mesquite-dominant landscapes in an ecosystem characterized by flux between woody shrubs, mesquite, and grasses. Albeit at a micro-scale, coalescence was observed during the study period. In the most extreme case, the largest patch began as 34 separate patches in 2011, down to 11 patches in 2012 (because of coalescence), and finally coalesced to one single patch by 2013.

Pennisetum ciliare invaded our site both through expansion along a front as well as through establishing satellite patches at a distance from existing patches. Controlling $P$. ciliare satellite patches potentially may be a more efficient strategy for preventing a runaway $P$. ciliare invasion compared to controlling large patches. The invasion attributes of dispersion pattern (i.e. satellite or invasion front) and patch expansion rate were straightforward to calculate and potentially provide critical information to inform control strategies. Future research linking satellite establishment and patch expansion to environmental variables, such as temperature and weather, as well as disturbance would further improve $P$. ciliare invasion models which in turn may offer greater control efficiency.

Acknowledgments: Field work was completed with the assistance of Josh Sutter, Rachel Turner, Grant Martin, Joey Dahms, and Andy Warnick. GIS analysis was completed with the assistance of Mickey Reed. No conflicts of interest have been declared. This work was supported by the U.S. Air Force's 56th Range Management Office at Luke Air Force Base, the Arizona Agricultural Experimental Station, and the Harry Wayne Springfield Endowment Scholarship. 


\section{References}

Bush JK, Van Auken OW (1987) Light requirements for growth of Prosopis glandulosa seedlings. Southwest Nat 32:469-473

Cannas SA, Marco DE, Montemurro MA (2006) Long range dispersal and spatial pattern formation in biological invasions. Math Biosci 203:155-170

Cox JR, Martin MH, Ibarra FA, Fourie JH, Rethman JFG, Wilcox DG (1988) The influence of climate and soils on the distribution of four African grasses. J Range Manag 41:127-139

D'Antonio C, Vitousek P (1992) Biological invasions by exotic grasses, the grass/fire cycle, and global change. Ann Rev Ecol Syst 23:63-87

Davis HG, Taylor CM, Civille JC, Strong DR (2004) An allee effect at the front of a plant invasion: Spartina in a pacific estuary. J Ecol 92:321-327

DiTomaso JM (2000) Invasive weeds in rangelands: Species, impacts, and management. Weed Sci 48:255-265

DiTomaso JM, Masters RA, Peterson VF (2010) Rangeland invasive plant management. Rangelands 32(1):43-47

[DOC-NOAA] (2018) National Environmental Satellite, Data, and Information Service. Gila Bend 3 ENE station. https://www.ncdc.noaa.gov/cdo-web. Accessed November 27, 2018

Ernst WHO, Veenendaal EM, Kebkile MM (1992) Possibilities for dispersal in annual and perennial grasses in a savannah in Botswana. Vegetatio 102:1-11

Fensham RJ, Donald S, Dwyer JM (2013) Propagule pressure, not fire or cattle grazing, promotes invasion of buffelgrass Cenchrus ciliaris. J Appl Ecol 50:138-146

Foody GM (2002) Status of land cover classification accuracy assessment. Remote Sens Environ 80:185-201

Higgins SI, Richardson DM, Cowling RM (1996) Modeling invasive plant spread: the role of plant-environment interactions and model structure. Ecology 77:2043-2054

Jernigan MB, McClaran MP, Biedenbender SH, Fehmi JS (2016) Uprooted buffelgrass thatch reduces buffelgrass seedling establishment. Arid Land Res Manag 30:320-329

Johnson WS, Shonkwiler JS (1999) The implications of variable or constant expansion rates in invasive weed infestations. Weed Sci 47:62-66

Lonsdale WM (1999) Global patterns of plant invasions and the concept of invasibility. Ecology, 80:1522-1536

Lookingbill TR, Minor ES, Bukach N, Ferrari JR, Wainger LA (2014) Incorporating risk of reinvasion to prioritize sites for invasive species management. Nat Area J 34:268-281

Lyons KG, Maldonado-Leal BG, Owen G (2013) Community and ecosystem effects of buffelgrass (Pennisetum ciliare) and nitrogen deposition in the Sonoran Desert. Invas Plant Sci Mana 6:65-78

McDonald CJ, McPherson GR (2011) Fire behavior characteristics of buffelgrass-fueled fires and native plant community composition in invaded patches. J Arid Environ 75:1147-1154

Molina-Montenegro MA, Carrasco-Urra F, Rodrigo C, Convey P, Valladares F, Gianoli E (2012) Occurrence of the non-native annual bluegrass on the Antarctic mainland and its negative effects on native plants. Conserv Biol 26:717-723

Moody M, Mack R (1988) Controlling the spread of plant invasions: the importance of nascent foci. J Appl Ecol 25:1009-1021 
Olsson AD, Betancourt JL, Crimmins MA, Marsh SE (2012a) Constancy of local spread rates for buffelgrass (Pennisetum ciliare L) in the Arizona Upland of the Sonoran Desert. J Arid Environ 87:136-143

Olsson AD, Betancourt JL, McClaran MP, Marsh SE (2012b) Sonoran desert ecosystem transformation by a C4 grass without the grass/fire cycle. Divers Distrib 18:10-21

Reynolds JF, Kemp PR, Ogle K, Fernández RJ (2004) Modifying the 'pulse-reserve' paradigm for deserts of North America: precipitation pulses, soil water, and plant responses. Oecologia 141:194-210

Richardson DM, Pyšek P (2006) Plant invasions: Merging the concepts of species invasiveness and community invasibility. Prog Phys Geog 30:409-431

Robinson TP, van Klinken RD, Metternicht G (2008) Spatial and temporal rates and patterns of mesquite (Prosopis species) invasion in Western Australia. J Arid Environ 72:175-188

Rogstad A (2008) The buffelgrass strategic plan. Arizona-Sonora Desert Museum, Tucson, AZ. 52p. https://www.desertmuseum.org/invaders/splan/buffelgrass_strategic_plan.pdf. Accessed March 17, 2016

Rossiter NA, Setterfield SA, Douglas MM, Hutley LB (2003) Testing the grass-fire cycle: Alien grass invasion in the tropical savannas of Northern Australia. Divers Distrib 9:169-176

Schramm JW, Ehrenfeld JG (2012) Patterns of patch colonization and expansion in the nonnative annual grass Microstegium vimineum (poaceae). Rhodora 114 (957):1-20

Sebert-Cuvillier E, Simonet M, Simon-Goyheneche V, Paccaut F, Goubet O, Decocq, G (2010) PRUNUS: a spatially explicit demographic model to study plant invasions in stochastic, heterogeneous environments. Biol Invasions 12:1183-1206

Shigesada N, Kawasaki K (1997) Biological invasions: theory and practice. Oxford, England: Oxford University Press. 205 p

van Auken OW, Bush JK (1990) Influence of light levels, soil nutrients, and competition on seedling growth of Baccharis neglecta (Asteraceae). B Torrey Bot Club 117:438-444

Ward JP, Smith SE, McClaran MP (2006) Water requirements for emergence of buffelgrass (Pennisetum ciliare). Weed Sci 54:720-725

Winkworth RE (1971) Longevity of buffelgrass seed sown in an arid Australian range. J Range Manag 24:141-145 


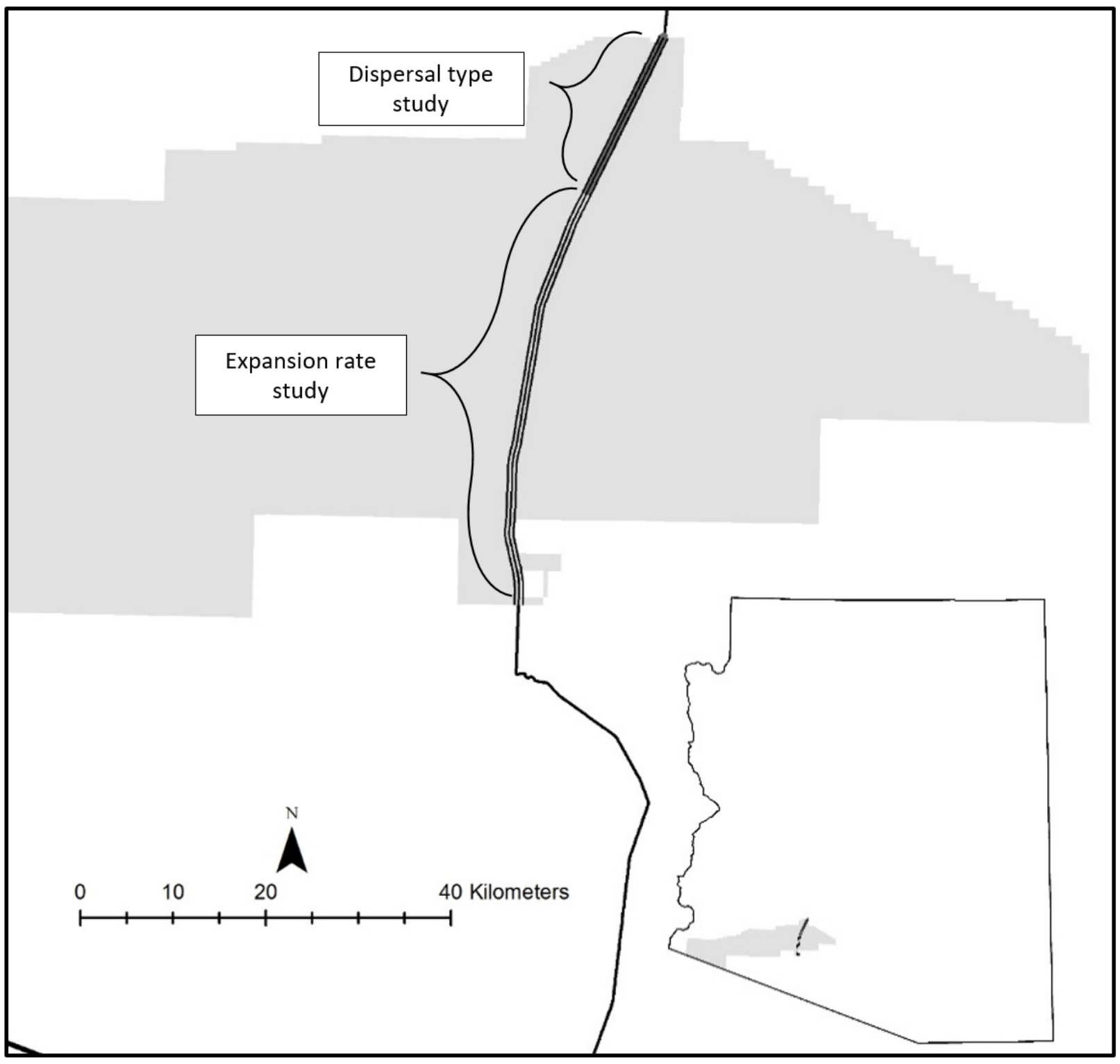

Figure 1. Map of the study area in Southwestern Arizona, USA. 


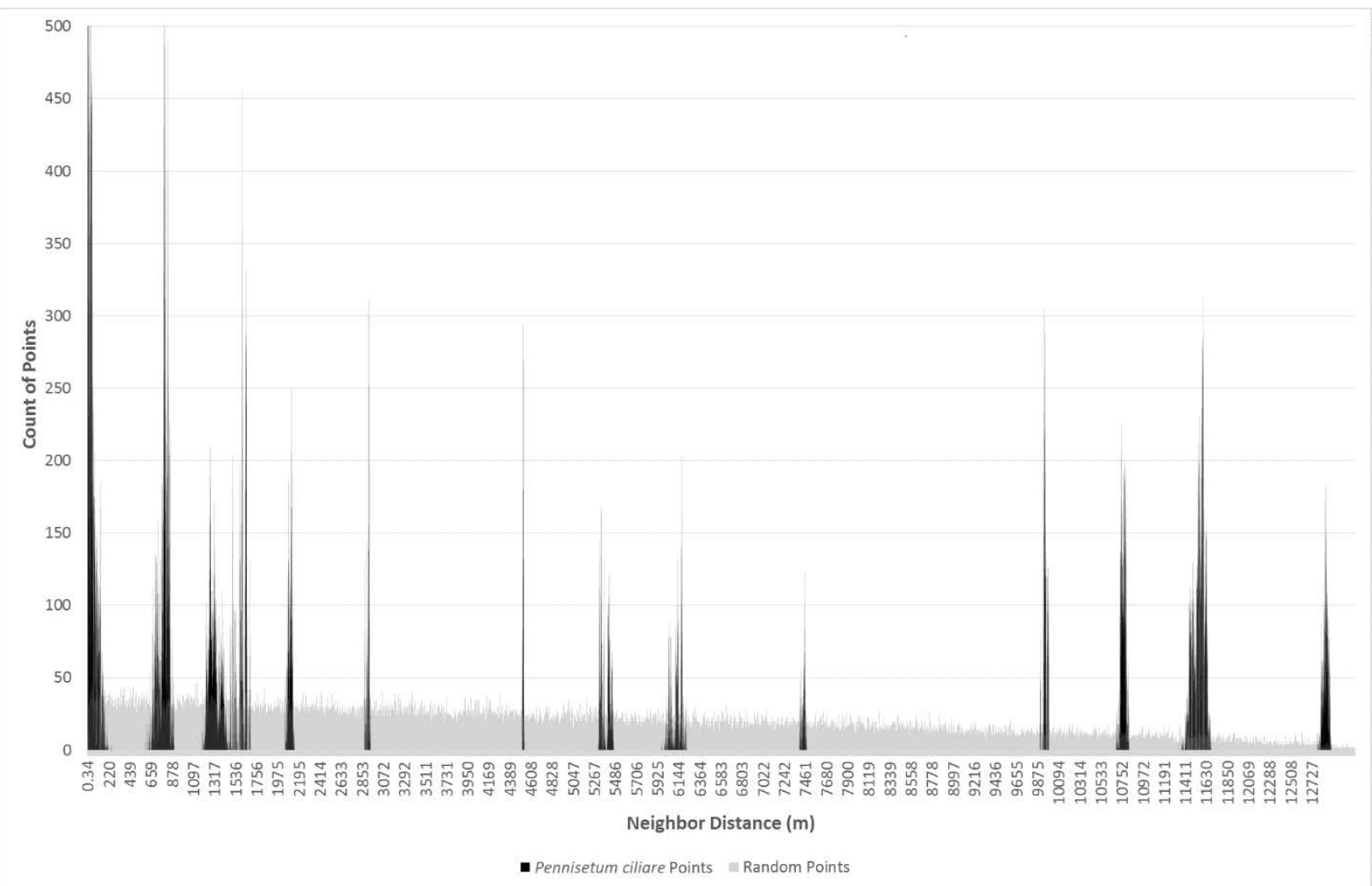

Figure 2. Frequency of nearest neighbor distances among all 652 P. ciliare points (black) and among 652 random points (gray) within the same study area constraint. The $P$. ciliare points are in 13 distinct spikes as opposed to the slightly decreasing trend of the random points (due to the shape of the road). The 13 spikes represent the possible distance combinations among 6 clusters. This is a visual representation of the satellite dispersal of the $P$. ciliare points. 


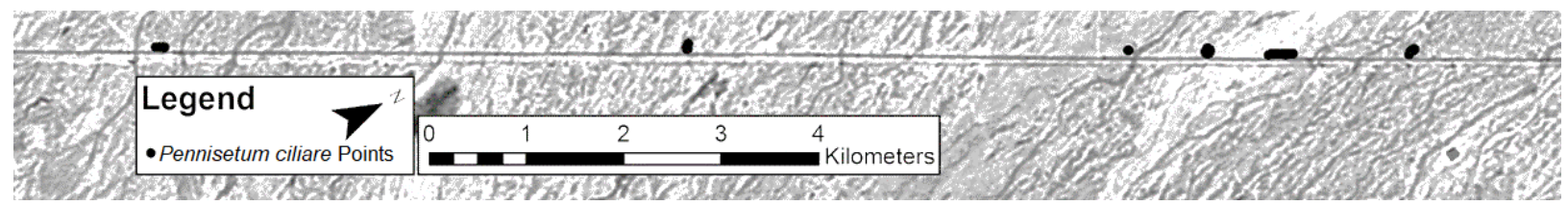

Figure 3. Map of the dispersal pattern study area showing the $652 P$. ciliare individuals which occur in six clusters.

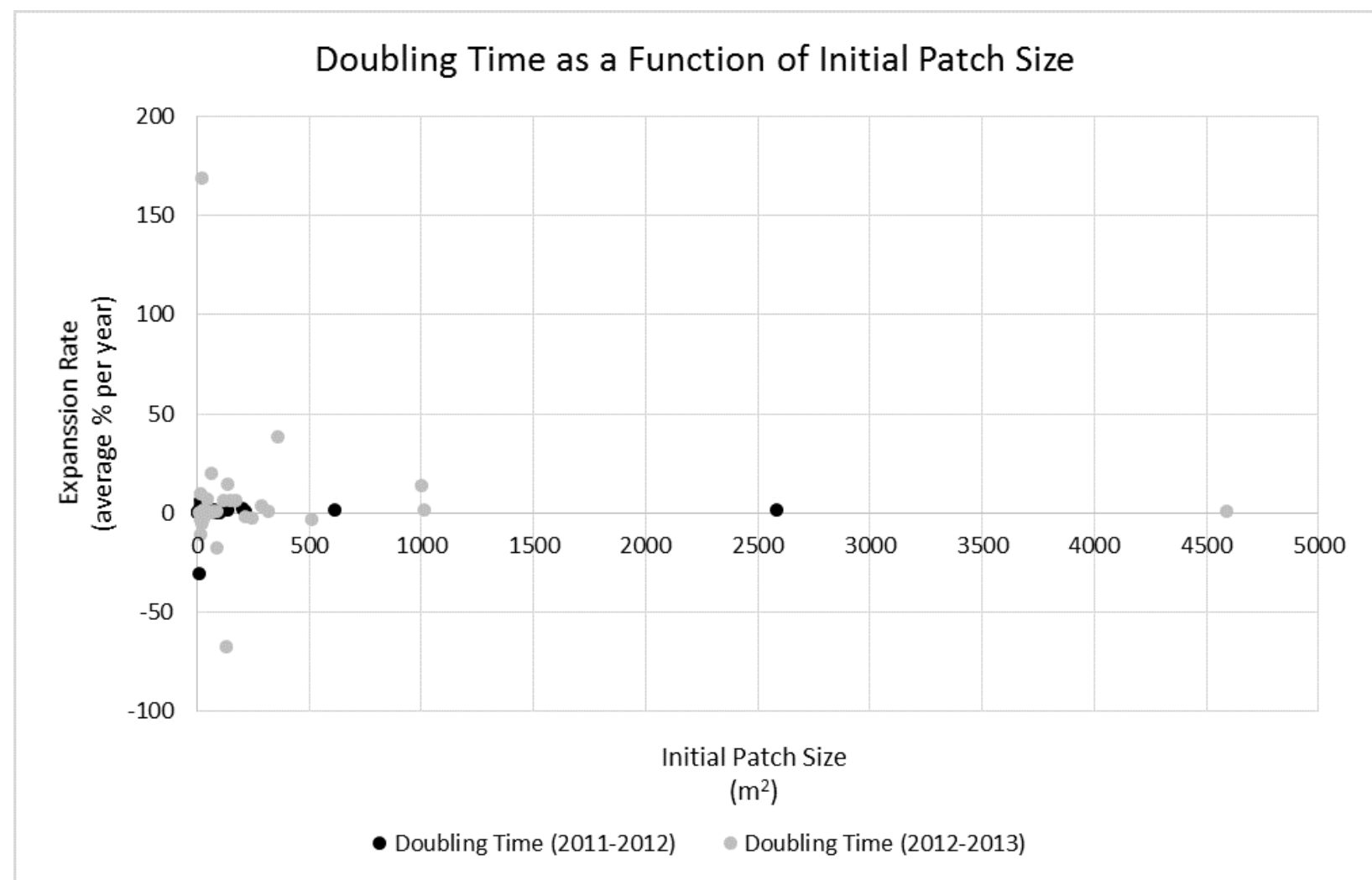

Figure 4. Relationship between expansion rate (percent change in area per year) and patch size (based on delineated patch outlines collected during the expansion rate study). $R^{2}=0.0048, p=$ 0.046 


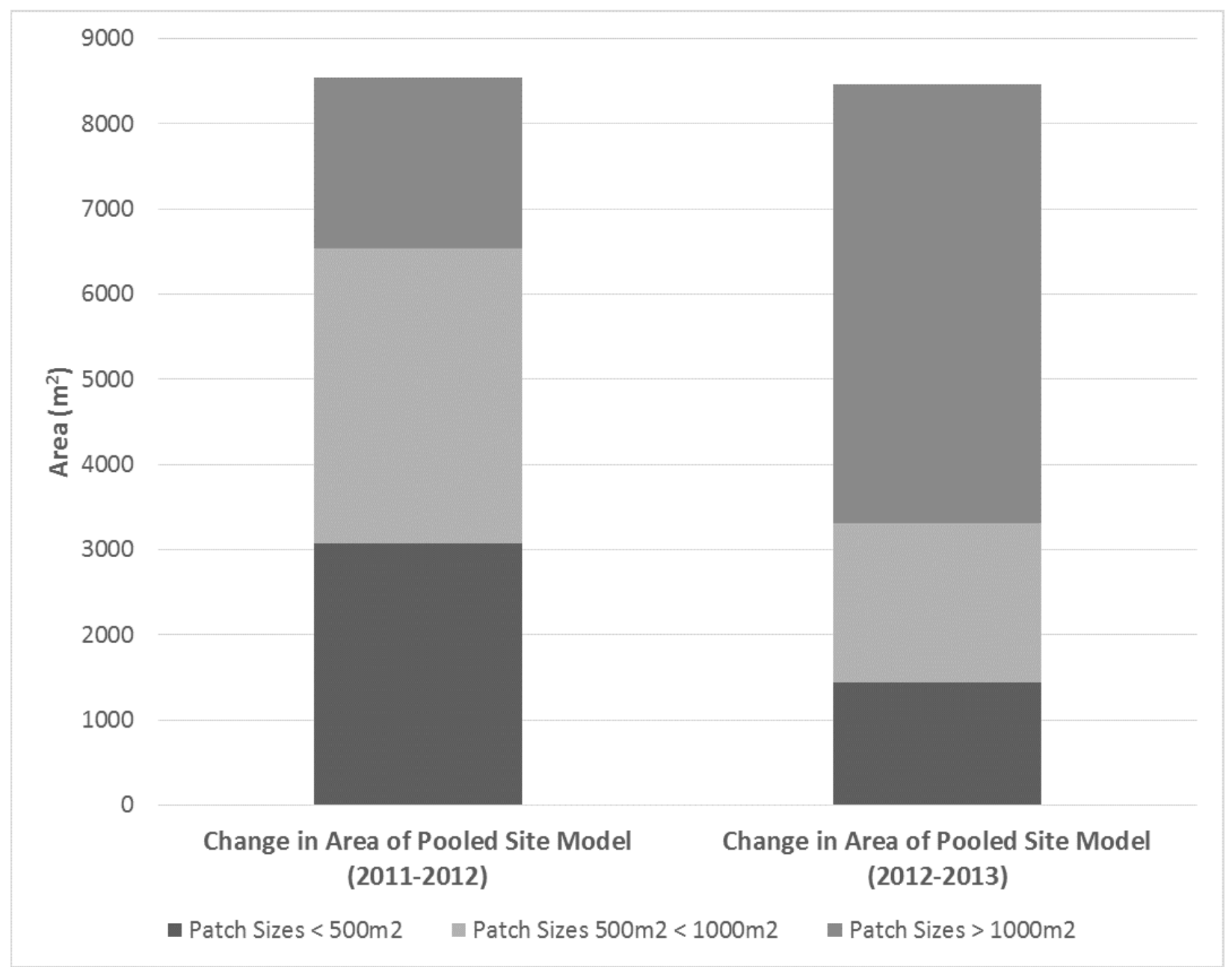

Figure 5. The pooled site model (PSM) expanded each year. The biggest contribution to the growth of the PSM, in terms of patch size, was different for both years. From 2011 to 2012, patches less than $1,000 \mathrm{~m}^{2}$ (satellites) contributed $63 \%$ of the growth to the PSM. Contrarily, from 2012 to 2013, patches less than 1,000 $\mathrm{m}^{2}$ contributed $27 \%$ of the growth to the PSM. 


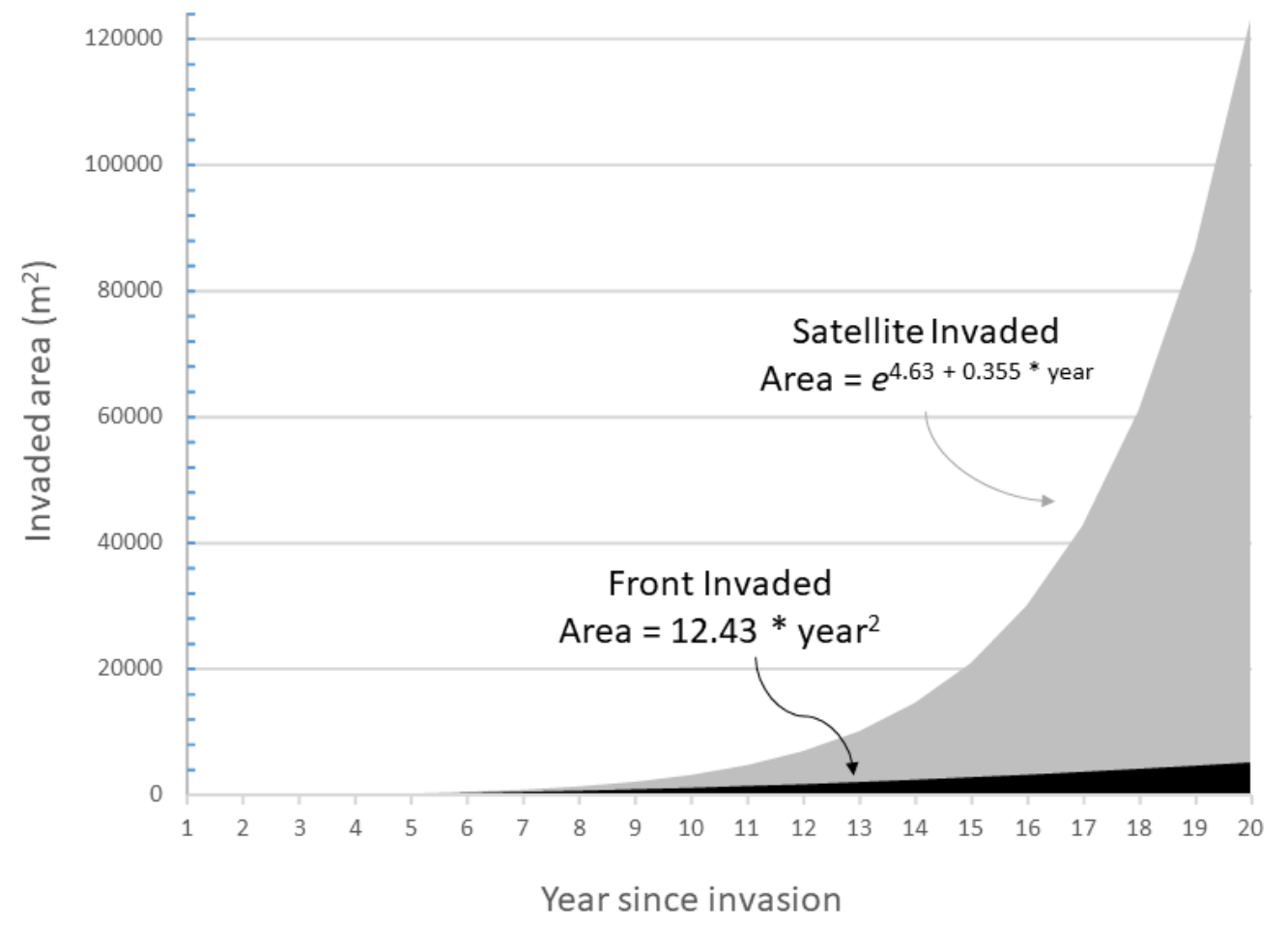

Figure 6. Graphical representation of invasion front versus satellite invasion as a function of time since establishment for $P$. ciliare. The expansion parameters were simplified from data collected on $P$. ciliare in this study. The expansion rates started in year 1 with a single plant of $0.25 \mathrm{~m}$ diameter. The front expansion remained a single patch. For satellite expansion, each patch spawned another patch every 2 years. All patches expanded by $2.11 \mathrm{~m}$ from their outer edge each year. Expansion was based on the assumptions of circular patches far enough apart to not coalesce and not constrained by lack of suitable growing space. The yearly values are plotted and formulae were fitted based on the cumulative outputs. 